\title{
Missed a beat: Is it your Ayurvedic drug?
}

\author{
Kavita S Joshi ${ }^{1}$, Gajanan A Panandikar ${ }^{2}$, Yogesh G Kuntalwad ${ }^{3}$, Smrati Bajpai ${ }^{4}$ \\ ${ }^{1}$ Dr Kavita S Joshi, Associate Professor, ${ }^{2}$ Dr Gajanan A Panandikar, Senior Resident, ${ }^{3}$ Dr Yogesh G Kuntalwad, Senior \\ Resident, ${ }^{4}$ Dr Smrati Bajpai, Assistant Professor. All are affiliated with Department of Medicine, Seth G S Medical \\ College, Parel, Mumbai, India.
}

Address for Correspondence: Dr. Kavita S Joshi, Associate Professor, Department of Medicine, Seth G S Medical College, Parel, Mumbai, India, Email: kavitajoshi@kem.edu

\begin{abstract}
24 year male presented with watery diarrhoea, 10-15 episodes/day since 2 days, vomiting, abdominal pain and giddiness since 1 day. Patient was hypotensive and had bradycardia. Rest of systemic examination was normal. ECG showed junctional bradycardia. Serum electrolytes, creatinine, Thyroid Function Tests were within normal limits. Troponin T levels were normal. On enquiry, patient gave history of ingestion of ayurvedic drug. Tribhuvankirtiras and mahashankvati for 1 day prior to symptoms, for dyspepsia. Patient was started on inotropic support with fluid correction for hypotension. Clinical diagnosis of arsenic and aconite toxicity was made. The drug samples showed high levels of Arsenic and Mercury. Aconite level could not be done due to unavailability of resources. Diagnosis of drug induced aconite and arsenic toxicity was made. With discontinuation of ayurvedic drugs and supportive management, patient improved symptomatically within 3 days with restoration of normal sinus rhythm.
\end{abstract}

Key words: Missed beat, junctional bradycardia, Ayurvedic drug, Tribhuvankirtiras.

\section{Introduction}

It is a common misconception that Ayurvedic medicines are safe and devoid of side effects [1, 2]. Ayurvedic medicines are used without prescription and regulation, as over the counter drugs [3]. The use of ayurvedic medicines is popular in India - and in recent times has become accepted in other countries. For example, a recent survey conducted by the NCCAM in the USA showed that about 751000 people in the United States had ever used ayurvedic drugs and 154000 people had used them within the past 12 months.

\begin{abstract}
Many ayurvedic preparations contain heavy metals like arsenic, mercury and also aconite. Incorrect dosage or formulation of these drugs can cause heavy metal toxicity, which can be life threatening leading to death [4]. This case highlights the importance of eliciting drug history in each patient and magnitude of complications of Ayurvedic medications, which is often neglected in clinical practice, and early diagnosis can help in appropriate management of toxicity in such cases.
\end{abstract}

\section{Case report}

A premorbidly healthy 24 year old male presented with complaints of loose motions, nausea and vomiting since 2 days, abdominal pain since 1 day, giddiness and blackout since 1 day. There was no history of palpitation, chest pain, fever, cough, reduced urine output, drug intoxication, addictions and no blood or mucus in stool.

No history of similar episodes in the past. There was no family history of cardiac disease or sudden death. On thorough enquiry for any drug consumption repeatedly, patient gave history of consumption of some Ayurvedic medications for dyspepsia. The drug given was found to be Tribhuvankirti Ras and mahashankvati, which was sent for chemical analysis for heavy metals.

Manuscript received $2^{\text {nd }}$ June 2016

Reviewed: $12^{\text {th }}$ June 2016

Author Corrected: $24^{\text {th }}$ June 2016

Accepted for Publication $7^{\text {th }}$ July 2016 


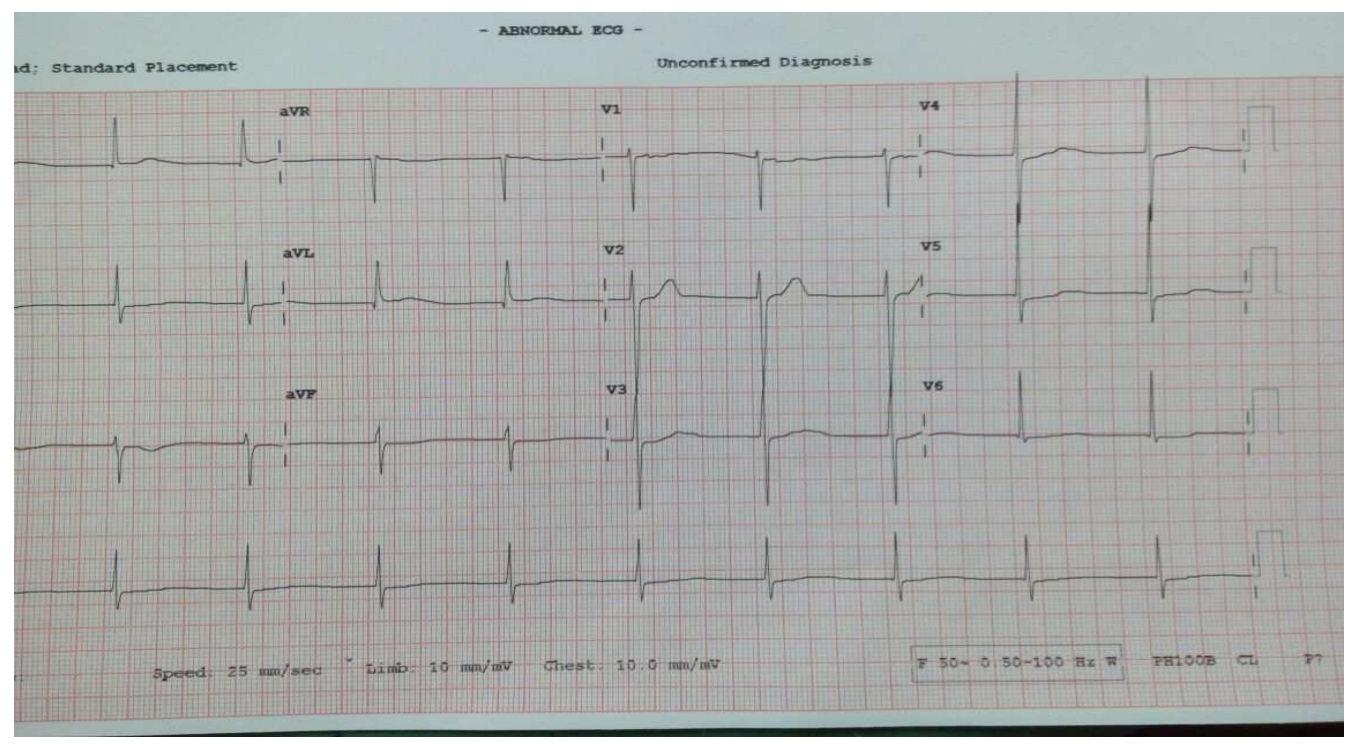

Figure-1: ECG at presentation showing junctional bradycardia

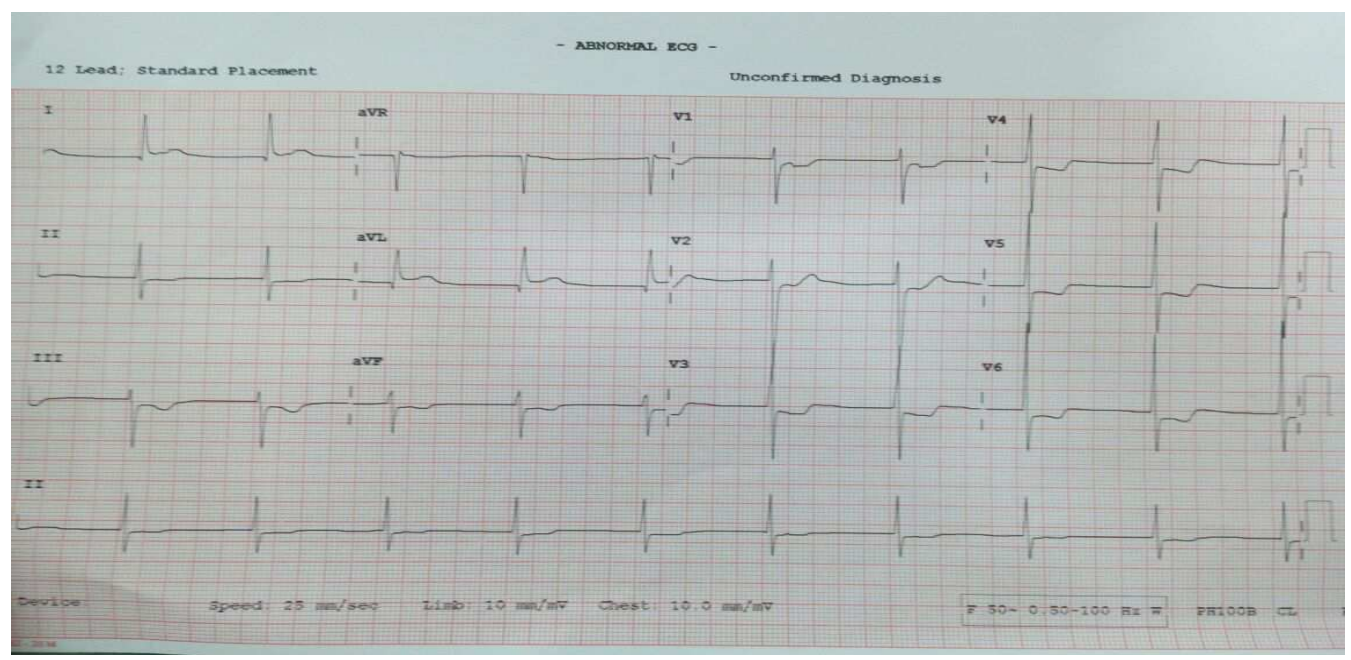

Figure-2: ECG after 2 hours of presentation showing junctional bradycardia with ST segment depression

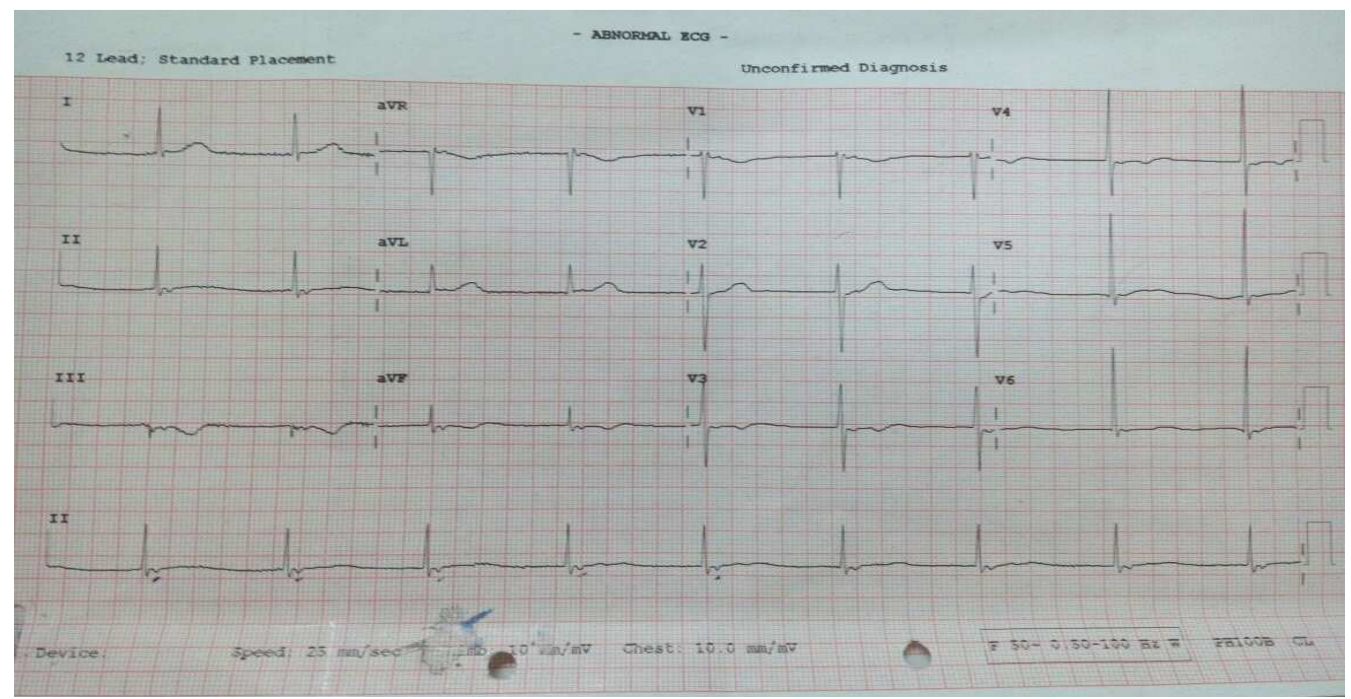

Figure-3: ECG at day 3 showing normal sinus rhythm 
ECG was suggestive of Junctional bradycardia, so serial ECG's were monitored. On examination, patient was conscious but restless. He had bradycardia with pulse rate of 50/min with regular rhythm. His extremities were cold. Blood pressure was 60/40 $\mathrm{mm}$ of $\mathrm{Hg}$ in supine position and $40 \mathrm{~mm}$ of $\mathrm{Hg}$ systolic BP in standing position. Jugular venous pressure was normal. No skin pigmentation or rash. Cardiovascular system examination was normal with normal heart sounds and no murmurs. Rest of systemic examination was normal.

Investigation- Patient had Junctional bradycardia on ECG with rate of 50/min. Serial ECG's were done. ECG at $2 \mathrm{hrs}$ of presentation showed ST segment depression in leads V2-V6 probably due to hypotension related transient cardiac ischemia.

Hemogram was normal. Serum electrolytes like potassium, sodium, calcium and magnesium were normal. Liver and renal function tests were normal. Serum levels of CPK-MB and troponin I were done to rule out acute coronary syndrome causing Junctional bradycardia, were all within normal limits. Thyroid function tests were normal.

Echocardiography was performed, which showed no regional wall hypokinesia with normal valves and ejection fraction of $60 \%$. Chest x-ray and abdominal ultrasonography was normal. Patient was clinically suspected to have aconite and arsenic toxicity in view of clinical symptoms. Serum aconite levels couldn't be done due to non availability of laboratory resources. The Ayurvedic drug samples were sent for heavy metal analysis which showed very high and toxic levels of arsenic and mercury.

Amount of Arsenic in the drug samples was 520ppm (stipulated limit-10ppm), and mercury was 20,800ppm (stipulated limit-1.0ppm)

So a diagnosis of drug induced aconite (in view of cardiac symptoms) and arsenic toxicity was made.

The differential diagnosis considered were

1. Ayurvedic drug induced arsenic and aconite toxicity

2. Acute gastroenteritis with dyselectrolytemia

Treatment- Patient was managed conservatively with hydration and inotropic support which was gradually tapered. On supportive management, sinus rhythm was restored by 3rd day. Patient improved clinically and was discharged.

\section{Discussion}

Ayurvedic drugs are a popular mode of therapy in India and are gaining popularity across the world due to globalisation. More than $70 \%$ of the total sales of Ayurvedic drugs are over-the-counter, thus leading to the use of ayurvedic medicines without prescription, guidance and oversight of Ayurvedic physicians [1].

Charaka Samhita, which is a classic text book of ayurveda says, "that even a strong poison can become an excellent medicine if administered properly. On the other hand even the most useful drug can act like a poison if handled carelessly" [5].

Vatsanabha (aconitum ferox) is a very well known ingredient of Tribhuvan Kirti Ras and Mahashankvati and is prescribed as an antipyretic, analgesic and appetite stimulant [6]. This is a very poisonous drug and should only be used with extreme caution and purification, and under the supervision of a qualified practitioner. It is used in India and Nepal in the treatment of neuralgia, leprosy, fever, cholera and rheumatism. It is also a used in Chinese herbal medication for rheumatism.

By a purification process, there is hydrolysis of aconite alkaloids into less toxic and non-toxic derivatives which is used for medical purposes.

Lin $\mathrm{CC}$ et al in a retrospective study of herb induced aconite poisoning described combination of neurologic, cardiovascular and gastrointestinal manifestation of aconite toxicity [7].

The major alkaloids are aconitine, bikhaconitine, diacetyl pseudaconitine, aconine, picro-aconine, veratry pseudaconitine, chamaconitine. 
The cardiotoxicity and neurotoxicity of aconitine and related alkaloids are due to their actions on the voltagesensitive sodium channels of the cell membranes of excitable tissues, including the myocardium, nerves, and muscles [8]. Aconitine and mesaconitine binds with high affinity to the open state of the voltage-sensitive sodium channels at site 2 , thereby causing a persistent activation of the sodium channels, which become refractory to excitation [9]. Arrhythmia induction is triggered due to delayed after-depolarization and early after-depolarization. The arrhythmogenic properties of aconitine are in part due to its anticholinergic effects mediated by the Vagus nerve. Aconitine has a positive inotropic effect by prolonging sodium influx during the action potential. It has hypotensive and bradycardic actions due to activation of the ventromedial nucleus of the hypothalamus. Through its action on voltagesensitive sodium channels in the axons, aconitine blocks neuromuscular transmission by decreasing the evoked quantal release of acetylcholine. Aconitine, mesaconitine, and hypaconitine can induce strong contractions of the ileum through acetylcholine release from the postganglionic cholinergic nerves.

Patients present predominantly with a combination of neurological, cardiovascular, and gastrointestinal features. The neurological features can be sensory (paresthesia and numbness of face, perioral area, and the four limbs), motor (muscle weakness in the four limbs), or both. The cardiovascular features include hypotension, chest pain, palpitations, bradycardia, sinus tachycardia, ventricular ectopics, ventricular tachycardia, and ventricular fibrillation. The gastrointestinal features include nausea, vomiting, abdominal pain, and diarrhea. The main causes of death are refractory ventricular arrhythmias and asystole and the overall in-hospital mortality is $5.5 \%$.

Arsenic and mercury are also ingredients of Tribhuvan kirti ras. In adult acute minimal lethal dose of arsenic estimated to be about $1 \mathrm{mg} / \mathrm{kg} /$ day. Acute arsenic toxicity manifests with tachycardia, watery stool, hypovolemic shock, arrhythemias, and long QT interval.

A study conducted by Joseph et al [10], showed the presence of heavy metals at levels more than the required recommendations by various health regulatory bodies, in some commercially available herbal medical products in India. The levels of Arsenic and Mercury calls for caution as far as their safe intake is concerned.
Our patient had gastrointestinal manifestation suggestive of arsenic toxicity but the junctional bradycardia and hypotension in our patient was suggestive of aconite toxicity as arsenic is known to cause QT prolongation not junctional bradycardia. There was temporal relationship of clinical manifestation with ayurvedic drug intake which has aconite as a constituent and other causes were ruled out. We may encounter patients who presents with adverse effects of Ayurvedic medicines as a medical emergency specially aconite. Due to gaining popularity of herbal preparations it is prudent to know the manifestation of heavy metal poisoning like arsenic, lead and also aconite which can be fatal if untreated and unrecognized.

Learning points: Due to the popularity of herbal preparations it is prudent to know the manifestation of heavy metal poisoning like arsenic, lead and also aconite which can be fatal if untreated and unrecognized.

Funding: Nil, Conflict of interest: None initiated. Permission from IRB: Yes

\section{References}

1. Thatte UM, Rege NN, Phatak SD, Dahanukar SA. The flip side of Ayurveda. J Postgrad Med. 1993 OctDec;39(4):179-82, 182a-182b.

2. Sarkar PK, Chaudhari S, Chattopadhyay A. Concept of interactions between consumable substances Ayurveda with special reference to foods and drugs. Drug Metabol Drug Interact. 2013;28(3):147-52. doi: 10.1515/dmdi-2013-0014.

3. Ernst E. Adverse effects of herbal drugs in dermatology. Br J Dermatol. 2000 Nov;143(5):923-9.

4. Shivamurthy RP, Kallappa R, Reddy SG, Rangappa DK. Steven-Johnson syndrome due to unknown drugs [corrected]. Indian J Pharmacol. 2012 Jan;44(1):134-5. doi: 10.4103/0253-7613.91888.

5. Acharya Jadavji Trikramji, editor. 5th ed. Varanasi: Chaukhambha Sanskrit Sansthan; 2001. "1 1 Adhyaya" Charak Samhita; p. 23.

6. Rastogi S, Rastogi R, Singh R. Adverse effects of Ayurvedic drugs: An overview of causes and possibilities in reference to a case of Vatsanabha (Aconite) overdosing. International Journal of Risk and Safety in Medicine. 2007; 19(3): 117-125. 
7. Panda AK, Debnath SK. Overdose effect of aconite containing Ayurvedic Medicine ('Mahashankha Vati'). Int J Ayurveda Res. 2010 Jul;1(3):183-6. doi: 10.4103/0974-7788.72493.

8. Lin CC, Chan TY, Deng JF. Clinical features and management of herb-induced aconitine poisoning. Ann Emerg Med. 2004 May;43(5):574-9.
9. Chan TY. Aconite poisoning. Clin Toxicol (Phila). 2009 Apr; 47 (4) : 279 - 85. doi: 10. 1080/ 15563650902904407.

10. Joseph SY, Varsha S, Kothari DC. Determination of mercury and arsenic content in a few Indian ayurvedic medicines by means of energy dispersive Xray fluorescence. Int J Pixe. 2009; 19(3): 77.

\section{How to cite this article?}

Kavita S Joshi, Gajanan A Panandikar, Yogesh G Kuntalwad, Smrati Bajpai. Missed a beat: Is it your Ayurvedic drug?. Int J Med Res Rev 2016;4 (7):1115-1119.doi: 10.17511/ijmrr.2016.i07.08. 